\title{
IMPACT OF REHABILITATION ON HEALTH RELATED QUALITY OF LIFE IN PATIENTS WITH HIP OSTEOARTHRITIS
}

Ana Divjak ${ }^{1}$, Dejan Aleksic ${ }^{1}$, Katarina Parezanovic Ilic ${ }^{1,2}$

${ }^{1}$ Faculty of Medical Sciences, University of Kragujevac, Serbia

${ }^{2}$ Service for physical medicine and rehabilitation, Clinical Center Kragujevac, Serbia

\author{
UTICAJ REHABILITACIJE NA KVALITET ŽIVOTA U VEZI SA \\ ZDRAVLJEM KOD PACIJENATA SA OSTEOARTRITISOM KUKA \\ Ana Divjak ${ }^{1}$, Dejan Aleksic ${ }^{1}$, Katarina Parezanovic Ilic ${ }^{1,2}$ \\ ${ }^{1}$ Fakultet medicinskih nauka, Univerzitet u Kragujevcu, Srbija \\ ${ }^{2}$ Služba za fizikalnu medicinu i rehabilitaciju, Klinički centar Kragujevac, Srbija
}

\begin{abstract}
Hip osteoarthritis (OA) is a degenerative, progressive musculoskeletal system disease in adult individuals. Both genders demonstrate a similar prevalence at $11.5 \%$ for men and $11.6 \%$ for women. During the initial stage of hip OA, conservative treatments may significantly decrease pain, provide functional improvement and enhance health related quality of life (HRQoL).

The aims of the study were to evaluate the quality of life of patients with hip osteoarthritis and to estimate the impact of a comprehensive rehabilitation intervention on their HRQDL.

This was a prospective, observational study of 50 consecutive patients with hip osteoarthritis who were referred to an outpatient rehabilitation intervention. To assess their HRQoL before and after rehabilitation, we used the SF-36 and the Lequesne index for hip $O A$.

The mean age was $61.7 \pm 8.3$ years, and $56 \%$ of the patients were women. After rehabilitation, the SF-36 RE and $R P$ subscales and the Lequesne pain subscale showed the most significant improvement, although all of the SF-36 and Lequesne domains showed significant improvement. Before rehabilitation, the Lequesne ADL subscale was most correlated with the SF-36 PF subscale (rho=-0.908). After rehabilitation, the total Lequesne score was highly correlated with the SF-36 PF subscale (rho=-0.895). Age, education and the duration of disease were significantly correlated with all of the Lequesne subscales before and after rehabilitation.

This study showed that patients with hip osteoarthritis had a substantially low HRQoL, but all health dimensions showed statistically significant improvements after outpatient rehabilitation intervention.
\end{abstract}

Keywords: Hip osteoarthritis, Rehabilitation, Health related quality of life

\section{SAŽETAK}

Osteoartritis (OA) kuka je degenerativna, progresivna bolest mišićnokoštanog sistema kod odraslih. Oba pola pokazuju sličnu učestalost od 11,5\% kod muškaraca i 11.6\% kod žena. U početnoj fazi OA kuka, konzervativni tretmani mogu značajno da smanje bol, obezbede funkcionalni napredak i poboljšaju kvalitet života u vezi sa zdravljem (HRQoL). Ciljevi: Ciljevi ove studije su bili evaluacija kvaliteta života pacijenata sa osteoartritisom kuka i procena uticaja sveobuhvatne rehabilitacione intervencije na njihov HRQoL.

Ovo je bila prospektivna, opservaciona studija kojom je obuhvaćeno 50 uzastopnih pacijenata sa osteoartritisom kuka koji su upućeni na ambulantnu rehabilitacionu intervenciju. Za procenu njihovog HRQoL pre i posle rehabilitacije koristili smo SF-36 i Lekejn indeks za osteoartritis kuka.

Prosečna starost je bila $61.7 \pm 8.3$ godina, $i 56 \%$ pacijenata su bile žene. Posle rehabilitacije, najznačajnije poboljšanje su pokazale SF-36 RE i RP subskale i Lekejn Pain subskala, ali su i svi SF-36 i Lekejn domeni pokazali značajno poboljšanje. Pre rehabilitacije, Lekejn $A D L$ subskala je najviše korelirala sa SF-36 PF subskalom (rho=-0.908). Posle rehabilitacije, Totalan Lekejn skor je jako korelirao sa SF-36 PF subskalom (rho=-0.895). Starost, obrazovanje i dužina trajanja bolesti su značajno korelirali sa svim Lekejn subskalama pre i posle rehabilitacije.

Ova studija je pokazala da pacijenti sa osteoartritisom kuka imaju žnačajno lošiji HRQoL, ali su sve dimenzije zdravlja pokazale statistički značajno poboljšanje posle ambulantne sveobuhvatne rehabilitacione intervencije.

Ključne reči: Osteoartritis kuka, Rehabilitacija, Kvalitet života u vezi sa zdravljem 


\section{ABBREVIATIONS}

\author{
ADL - Activity of Daily Living \\ BP - Bodily Pain \\ GH - General Health perceptions \\ HRQoL - Health related quality of life \\ IFS - Interferential current stimulation \\ MH - Mental Health \\ OA - Osteoarthritis
}

PF - Physical Functioning

PEMF - Pulsed electromagnetic field therapy

RE - Emotional Role

RP - Physical Role

SF - Social Functioning

SF-36 - 36-Item Short Form Health Survey

VT - Vitality

\section{INTRODUCTION}

Hip osteoarthritis $(\mathrm{OA})$ is a degenerative, progressive musculoskeletal system disease in adult individuals (1). It is firstly characterized by both progressive articular cartilage loss (2, 3) and appositional new bone formation in the subchondral trabeculae at the joint margins (osteophytes) (3). Hip OA is a disorder ubiquitous all over the world, specifically in the elderly. Because of differences in the definition of OA, such as those based on radiographs, symptoms, or self-report as well as differences in the characteristics of study samples, the estimated prevalence of hip OA greatly differs among studies. The prevalence rates are higher among studies that used the radiographic definition of OA than among studies that used the self-reported or symptomatic definition, varying from $0.9 \%$ to $45 \%$. Both genders demonstrate similar prevalences at $11.6 \%$ for women and $11.5 \%$ for men.

Hip OA is a strongly disabling condition. A major symptom is pain, and as the disease progresses, the pain becomes permanent and more restricting (4). Patients also complain about functional impairment in everyday activities, such as walking, stair climbing, car driving, and household and garden working, and they report symptoms of anxiety and depression. These limitations in physical activity and pain are further accompanied with a deterioration in quality of life (4-7). Hip OA has an unfavourable natural course as the intensity of symptoms and the degree of disability have a tendency to increase over time (8).

During the initial stage of the disease, conservative treatments may significantly decrease pain, provide functional improvement, and enhance health related quality of life (HRQoL). In this context, the appropriate options for therapeutic management are physical therapy and physical exercise programmes. However, joint replacement is needed to manage the disease during the advanced stage (5).

Although quality of life cannot be described with bodily symptoms or the absence of an illness, social and emotional perceptions have an impact on this concept (9). HRQoL uses measurements of health outcomes that have been demonstrated to affect patients (7). This concept is frequently applied to describe the impact of a disease or intervention on an individual, but studies have used more than one definition. The World Health Organization (WHO) defines quality of life as an individual's self-perception of life within the context of their living conditions, culture and values. HRQoL tools measure the influence of health status on life and encompass the physical, emotional and social dimensions of health (10).

The aims of the present study were to evaluate the quality of life of patients with hip osteoarthritis and to estimate the impact of a comprehensive rehabilitation intervention on their HRQoL.

\section{MATERIALS AND METHODS}

This was a prospective, observational, descriptive study of 50 patients with hip OA. The patients were recruited from the services for physical medicine and rehabilitation of the Clinical Center Kragujevac. From September 2015 to December 2015, all patients with hip osteoarthritis were consecutively asked to participate in the study and referred to an outpatient rehabilitation intervention. The study was approved by the ethics committee of the Clinical Center Kragujevac. We explained the purpose, risks and benefits of the study to all patients, and they gave their verbal consent to participate.

The inclusion criteria were as follows: patients of either gender, patients aged greater than 40 years old and patients with primary hip osteoarthritis. The exclusion criteria were as follows: patients with concomitant systemic inflammatory rheumatic diseases; patients in the terminal stage of malignancy; patients with severe respiratory, heart or renal failure; patients with peripheral vascular diseases of the lower extremities; patients with psychiatric disorders and patients who refused to participate in the study.

The patients received the same comprehensive rehabilitation intervention. It consisted of physical therapy, which comprised pulsed electromagnetic field therapy (PEMF) and interferential current stimulation (IFS), and therapeutic exercises. The PEMF therapy was performed using a Magomil 2 (Electronic Design, Belgrade), which emits a low-frequency field. The intensity of the magnetic field was $20 \mathrm{mT}$, and its frequency was $99 \mathrm{~Hz}$. All patients underwent a 30-minute treatment of PEMF therapy five times per week for a period of two weeks. IFS was delivered using an alternating current generator (IF53, PROXIMA, Niš) with a medium frequency. All patients received IFS therapy at a frequency from 1 to $100 \mathrm{~Hz}$ and at a tolerable intensity. It was applied once a day for 20 minutes, five times per week, over a two-week period. 
The therapeutic exercises involved flexibility (range of motion) exercises in conjunction with strength exercises that were intended to maintain or improve hip joint mobility and to increase the muscle strength of the hip joint stabilizer. The exercise therapy programme comprised an individual, physiotherapist-supervised session that lasted for 30 minutes five times per week over the two-week period.

The included patients were interviewed by the same physician before (baseline) and after rehabilitation (follow up). Socio-demographic and clinical data, such as gender, age, the level of education and the duration of disease, were collected for every patient through a personal interview. We used the 36-Item Short Form Health Survey (SF-36) to assess patient HRQoL. It is a generic instrument composed of 36 items that measures eight domains of health status by self-report. Physical functioning, physical role, bodily pain and general health perceptions are the four domains that estimate physical health. The other four domains, vitality, social functioning, emotional role, and mental health, evaluate mental health. As there is no total score, each domain is analysed individually and is scored from 0 to 100 , where a lower score correlates with a lower health status $(7,11,12)$.

We also used the Lequesne algofunctional index to assess HRQoL among those with hip osteoarthritis. It is a disease-specific instrument that gathers information about symptoms and physical function. It is an 11-item questionnaire composed of three sections; five items address pain or discomfort, two items address the maximum distance walked and whether a walking aid is required and four items address activities of daily living. Each domain is scored from 0 to 8 , and the sum of all items is the Lequesne index score, which ranges from 0 to 24 . A higher score correlates with a poorer status of health. A total index score from 1 to 4 indicates mild disability, from 5 to 7 indicates moderate disability, from 8 to 10 indicates severe disability, from 11 to 13 indicates very severe disability and equal or greater than 14 indicates extremely severe disability $(11,13)$.

The statistical analyses were performed by using the statistical software package SPSS version 20.0 for Windows (SPSS Inc.). All domains of the SF-36 and Lequesne index were not normally distributed, and Wilcoxon's rank sum test was used to analyse the change in scores of both instruments before and after the rehabilitation intervention. Spearman's correlation coefficient was calculated as measure of the association intensity to assess the correlations among all domains of the SF-36 and Lequesne index. A non-parametric Mann-Whitney U test was used to compare differences between genders. The results are expressed as the means \pm standard deviations. The alpha level for significance was set to $\mathrm{p} \leq 0.05$.

\section{RESULTS}

The sample consisted of 50 patients whose mean age was $61.7 \pm 8.3$ years (range from 47 to 75 years), and $56 \%$ of the patients were women. A total of $60 \%$ of the patients had received a secondary school education, $22 \%$ had a high school/university education and $18 \%$ had a primary school education. The mean duration of disease was $4.42 \pm 2.5$ years (range from 1 to 10 years).

Table 1 summarizes the mean, median, and interquartile range for each domain of the SF-36 and Lequesne index. After the comprehensive rehabilitation intervention, the SF-36 RP and RE subscale scores were significantly improved compared with the scores for these domains at

Table 1: Descriptive statistics and features of score distributions for health status measures in hip osteoarthritis patients ( $\mathrm{n}=50$ )

\begin{tabular}{|c|c|c|c|c|c|c|c|c|}
\hline \multirow[t]{2}{*}{ SF-36 } & \multirow[t]{2}{*}{$\begin{array}{l}\text { Mean } \\
\pm \text { SD }^{1}\end{array}$} & \multirow[t]{2}{*}{ Median $^{1}$} & \multirow[t]{2}{*}{$\begin{array}{l}\text { Interquartile } \\
(25 \text { th-75th })^{1}\end{array}$} & \multirow[t]{2}{*}{$\begin{array}{l}\text { Mean } \\
\pm \mathrm{SD}^{2}\end{array}$} & \multirow[t]{2}{*}{ Median $^{2}$} & \multirow[t]{2}{*}{$\begin{array}{l}\text { Interquartile } \\
\text { (25th-75th })^{2}\end{array}$} & \multicolumn{2}{|c|}{ Wilcoxon's rank test } \\
\hline & & & & & & & $\mathrm{Z}$ & $\mathrm{P}$ \\
\hline $\mathrm{PF}$ & $38.7 \pm 25.7$ & 40.0 & $10.0-60.0$ & $73.5 \pm 23.7$ & 80.0 & $48.7-95.0$ & -6.168 & **: \\
\hline $\mathrm{RP}$ & $13.0 \pm 23.8$ & 0.0 & $0.0-25.0$ & $78.0 \pm 23.5$ & 75.0 & $68.8-100.0$ & -6.115 & **: \\
\hline RE & $14.0 \pm 23.4$ & 0.0 & $0.0-33.3$ & $82.0 \pm 26.3$ & 100.0 & $66.7-100.0$ & -6.151 & *** \\
\hline VT & $32.2 \pm 21.4$ & 35.0 & $10.0-51.2$ & $81.8 \pm 21.1$ & 55.0 & $30.0-70.0$ & -6.432 & $* *$ \\
\hline $\mathrm{MH}$ & $47.9 \pm 16.3$ & 48.0 & $36.0-64.0$ & $66.1 \pm 15.2$ & 68.0 & $56.0-80.0$ & -6.482 & $* *$ \\
\hline SF & $31.2 \pm 22.3$ & 31.2 & $12.5-50.0$ & $58.5 \pm 23.1$ & 62.5 & $37.5-75.0$ & -6.543 & $* *$ \\
\hline $\mathrm{BP}$ & $27.6 \pm 19.3$ & 32.5 & $10.0-45.0$ & $55.2 \pm 21.5$ & 55.0 & $32.5-77.5$ & -6.306 & $*:$ \\
\hline $\mathrm{GH}$ & $35.1 \pm 20.5$ & 37.5 & $15.0-55.0$ & $59.3 \pm 20.4$ & 60.0 & $40.0-80.0$ & -6.252 & $\because *$ \\
\hline \multicolumn{9}{|l|}{ Lequesne } \\
\hline Pain & $5.1 \pm 1.8$ & 4.5 & $4.0-7.0$ & $1.6 \pm 1.8$ & 1.0 & $0.0-3.0$ & -6.202 & $* *$ \\
\hline Distance & $3.8 \pm 2.2$ & 3.0 & $2.0-6.0$ & $2.5 \pm 2.0$ & 2.0 & $1.0-4.0$ & -6.029 & $* *$ \\
\hline ADL & $7.7 \pm 4.1$ & 7.5 & $4.0-12.0$ & $4.7 \pm 3.7$ & 4.5 & $2.0-8.0$ & -5.997 & $* *$ \\
\hline Total & $16.5 \pm 7.7$ & 16.0 & $10.0-24.0$ & $8.7 \pm 6.4$ & 7.0 & $3-0-15.0$ & -6.175 & $* *$ \\
\hline
\end{tabular}

SF-36- 36-Item Short Form Health Survey; PF-Physical Functioning; RP-Physical Role; RE- Emotional Role; VT - Vitality; MH - Mental Health; SF Social Functioning; BP- Bodily Pain; GH - General Health perceptions; ADL-Activity of Daily Living.

${ }^{1}$ Before rehabilitation

${ }^{2}$ After rehabilitation

* $\mathrm{p} \leq 0.05{ }^{* * *} \mathrm{p} \leq 0.01$ 
Table 2: Spearman's correlation coefficient of SF-36 and Lequesne subscale scores for patients with hip ossteoarthritis

\begin{tabular}{|c|c|c|c|c|c|c|c|c|}
\hline \multicolumn{9}{|c|}{ SF-36 } \\
\hline Lequesne & $\mathrm{PF}^{1}$ & $\mathrm{RP}^{1}$ & $\mathrm{RE}^{1}$ & $\mathrm{VT}^{1}$ & $\mathrm{MH}^{1}$ & $\mathrm{SF}^{1}$ & $\mathrm{BP}^{1}$ & $\mathrm{GH}^{1}$ \\
\hline Pain $^{1}$ & $-0.712^{* * *}$ & $-0.427^{*}$ & $-0.569 *$ & $-0.750^{* * *}$ & $-0.637^{* *}$ & $-0.668^{* *}$ & $-0.626^{* * *}$ & $-0.702^{* * *}$ \\
\hline Distance $^{1}$ & $-0.871^{* * *}$ & $-0.513^{* * *}$ & $-0.611^{* * *}$ & $-0.789^{* * *}$ & $-0.724^{* * *}$ & $-0.751^{* *}$ & $-0.745^{* * *}$ & $-0.721^{* * *}$ \\
\hline $\mathrm{ADL}^{1}$ & $-0.908^{* * *}$ & $-0.436^{*}$ & $-0.582^{* * *}$ & $-0.796^{* * *}$ & $-0.652^{* *}$ & $-0.744^{* * *}$ & $-0.777^{* * *}$ & $-0.714^{* *}$ \\
\hline Total $^{1}$ & $-0.907^{* * * *}$ & $-0.486^{* * * *}$ & $-0.627^{* * *}$ & $-0.841^{* * *}$ & $-0.726^{* * *}$ & $-0.784^{* * *}$ & $-0.780^{* * * *}$ & $-0.765^{* * *}$ \\
\hline Lequesne & $\mathrm{PF}^{2}$ & $\mathrm{RP}^{2}$ & $\mathrm{RE}^{2}$ & $\mathrm{VT}^{2}$ & $\mathrm{MH}^{2}$ & $\mathrm{SF}^{2}$ & $\mathrm{BP}^{2}$ & $\mathrm{GH}^{2}$ \\
\hline Pain $^{2}$ & $-0.669^{* *}$ & $-0.388^{*}$ & $-0.441 *$ & $-0.620^{* *}$ & $-0.630 \%$ & $-0.579 *$ & $-0.528^{* * *}$ & $-0.583^{* *}$ \\
\hline Distance $^{2}$ & $-0.832^{* * *}$ & $-0.641^{* * *}$ & $-0.479 * \%$ & $-0.808^{* * *}$ & $-0.711^{* *}$ & $-0.779^{* * *}$ & $-0.782^{* * *}$ & $-0.720^{* * *}$ \\
\hline $\mathrm{ADL}^{2}$ & $-0.866^{* * *}$ & $-0.550^{* * *}$ & $-0.584^{* *}$ & $-0.730^{* * *}$ & $-0.606^{* \%}$ & $-0.707^{* * *}$ & $-0.706^{* * *}$ & $-0.684 \%$ \\
\hline Total $^{2}$ & $-0.895^{* * *}$ & $-0.602^{* * *}$ & $-0.683 *$ & $-0.811^{* * *}$ & $-0.733^{* *}$ & $-0.789^{* *}$ & $-0.767^{* * *}$ & $-0.741^{* * *}$ \\
\hline
\end{tabular}

SF-36- 36-Item Short Form Health Survey; PF-Physical Functioning; RP-Physical Role; RE- Emotional Role; VT - Vitality; MH - Mental Health; SF Social Functioning; BP- Bodily Pain; GH - General Health perceptions; ADL-Activity of Daily Living.

${ }^{1}$ Before rehabilitation

${ }^{2}$ After rehabilitation

* $\mathrm{p} \leq 0.05$ ** $\mathrm{p} \leq 0.01$

baseline. For the SF-36, the RE and RP domains achieved the largest improvement, while the GH domain showed the smallest improvement. For the Lequesne index, the pain domain showed the most significant improvement. All health dimensions of the SF-36 and Lequesne index showed significant improvement after intervention as observed in table 1.

We also investigated the associations of all of the SF-36 subscales with all of the Lequesne subscales before and after comprehensive rehabilitation intervention. As shown in table 2, before rehabilitation, we found that the Lequesne ADL subscale was better correlated with the SF-36 PF subscale $(\mathrm{rho}=-0.908)$ than the rest of the SF-36 subscales. The total Lequesne score was highly correlated with the SF-36 PF subscale (rho $=-0.895)$ after rehabilitation. The Pearson correlation coefficients were negative between the Lequesne subscales and the SF-36 subscales, indicating that the scores decreased with improvements in HRQoL. All associations were highly correlated, but only the correlations between the Lequesne ADL subscale and the SF-36 $\mathrm{RP}$ before rehabilitation and between the Lequesne pain subscale and the SF-36 RP after rehabilitation were statistically significant.
Table 3 shows significantly positive correlations of age and the duration of disease with all of the Lequesne domains. There were also significant negative correlations between education and all of the Lequesne subscales. There were no statistically significant differences in all of the Lequesne domains before and after rehabilitation between women and men.

\section{DISCUSSION}

In our study, the mean age of patients with hip OA was $61.7 \pm 8.3$ years, which was similar to the mean age reported in other studies. The majority were women, corresponding to the sex distribution of cohorts from other studies $(7,14-$ 19). The education level of our patients was, on average, higher than that of patients in other studies; the majority of the populations from those studies had completed up to primary school $(14,15,17)$ or were illiterate $(17,18)$. The average duration of hip OA in our group of patients was $4.42 \pm 2.5$ years, which was similar to that reported by Boutron et al. $(5.4 \pm 4.8$ years; $n=1581)$ and other studies $(15,17,18)$.Before rehabilitation, our patients showed low

Table 3: Spearman's correlation coefficients between socio-demographic and clinical characteristics and Lequesne subscale scores

\begin{tabular}{|c|c|c|c|c|}
\hline Lequesne $^{\mathrm{a}}$ & $\mathrm{Age}^{\mathrm{a}}$ & Education $^{\mathrm{a}}$ & Duration of disease $^{a}$ & Gender $^{b}$ \\
\hline Pain $^{1}$ & $0.547^{* * *}$ & $-0.521^{* * *}$ & $0.684^{* * *}$ & $Z=-1.005$ \\
\hline Distance $^{1}$ & $0.775^{* *}$ & $-0.542^{* * *}$ & $0.794^{* * *}$ & $Z=-0.406$ \\
\hline $\mathrm{ADL}^{1}$ & $0.833 \%$ & $-0.653^{* * *}$ & $0.841^{* *}$ & $Z=-0.461$ \\
\hline Total $^{1}$ & $0.798 \%$ & $-0.615^{* * *}$ & $0.842^{* * *}$ & $Z=-0.577$ \\
\hline Pain $^{2}$ & $0.433^{*}$ & $-0.471^{* *}$ & $0.558 * *$ & $Z=-0.524$ \\
\hline Distance $^{2}$ & $0.788^{* * *}$ & $-0.538^{* *}$ & $0.777^{* * *}$ & $Z=-0.020$ \\
\hline $\mathrm{ADL}^{2}$ & $0.793^{* *}$ & $-0.601^{* * *}$ & $0.730^{* * *}$ & $Z=-0.390$ \\
\hline Total $^{2}$ & $0.774 * *$ & $-0.627^{* * *}$ & $0.780 \% *$ & $\mathrm{Z}=-0.118$ \\
\hline
\end{tabular}

a Spearman's correlation

${ }^{\mathrm{b}}$ non-parametric Mann-Whitney U test 
average scores for the RP, RE and BP domains of the SF-36. In fact, the average SF-36 RP domain score reported in this study was lower than that recorded in other studies (12, 14, 20-23), while Krauss et al. reported the highest score for this domain (5). After rehabilitation, the SF-36 RP domain showed the greatest improvement, followed by the RE domain. These results were consistent with the results of other studies $(19,20)$, although one study observed lower scores in the SF-36 RP domain after rehabilitation (23). The SF-36 RS domain showed the largest improvement after rehabilitation; this finding contradicted the results observed in other studies $(14,19,23)$, with some studies reporting high scores for that domain before rehabilitation $(1,12)$. Generally, hip OA patients receive low scores for the SF-36 BP domain $(1,12,14,15,19-24)$, which was in accordance with our results; thus, after rehabilitation, this was one of the domains that showed moderate improvement in our patients, although other studies reported that this domain showed the greatest improvement (14-16, 20, 23, 25). A Cochrane review from 2014 (26) included nine studies (549 patients) and showed that exercise therapy reduces pain and improves physical function immediately after treatment. After rehabilitation, there was a significant improvement in the SF-36 VT domain; this finding was in agreement with the results from other studies $(6,23)$. This domain was the second highest in score, immediately after the RE domain. After rehabilitation, statistically significant improvements were shown in all SF-36 domains $(20,24)$.

Before rehabilitation, our patients scored an average total Lequesne index score of $16.5 \pm 7.7$ (extremely severe). Similar studies demonstrated serious disability in their study populations with total Lequesne scores that ranged from 10.51 to $13.67(11,14,17,18)$. In our study, the worst score for the Lequesne index was in the ADL domain; this was also reported in the study by Konstantinidis et al. (11). However, in the studies by Basaran et al. (18) and Nadrian et al. (17), the pain domain showed the worst score. After rehabilitation, statistically significant improvements were observed in all domains of the Lequesne index.

Before rehabilitation, our results showed that the Lequesne ADL domain was most significantly correlated with the SF-36 PF domain; however, Konstantinidis et al. (11) found that the strongest significant correlation existed between the Lequesne ADL domain and the SF-36 SF domain. The correlations among all other subscales in the present study were significant and negative, whereas in the aforementioned study, the correlations among the other subscales were also negative but not statistically significant. In a study by Basaran et al., all of the Lequesne subscales showed a moderate correlation with the SF-36 PF and BP subscales, but the relationships lacked statistical significance (18).

Our study also noted that there were significant positive correlations between all of the Lequesne subscales (except for pain after rehabilitation) and the age of the patient, which was confirmed in the study by Nadrian et al. (17). According to the results from Konstantinidis et al. (11), a significant positive correlation only existed between age and the Lequesne distance subscale, indicating that the correlations of age with the other subscales were not significant. Education showed significant negative correlations with all of the Lequesne subscales in our study and in the study by Nadrian et al. (17). Moreover, we found significant positive correlations between the duration of disease and all of the Lequesne subscales before and after rehabilitation, while Nadrian et al. (17) observed a significant positive correlation between the pain domain and the total Lequesne score and also between the Lequesne distance and ADL subscale scores. In a study by Basaran et al. (18), age, education and the duration of the disease did not show significant correlations with all of the Lequesne subscales.

\section{CONCLUSION}

According to the results of this study, patients with hip OA had a substantially low HRQoL. This study also showed significant improvements in all health dimensions of patients who underwent an outpatient, comprehensive rehabilitation intervention, as evaluated by both the generic SF-36 and disease-specific Lequesne index for hip OA.

\section{REFERENCES}

1. Krauß, I., Steinhilber, B. \& Haupt, G. (2014). Exercise therapy in hip osteoarthritis--a randomized controlled trial. Dtsch Arztebl Int. 111(35-36), 592-9. DOI: 10.3238/arztebl.2014.0592.

2. Hofstede, SN., Vliet Vlieland, TP. \& van den Ende, CH. (2014). Designing a strategy to implement optimal conservative treatments in patients with knee or hip osteoarthritis in orthopedic practice: a study protocol of the BART-OP study. Implement Sci. 9-22. DOI: 10.1186/1748-5908-9-22.

3. Stemberger, R.\& Kerschan-Schindl, K. (2013). Osteoarthritis: physical medicine and rehabilitation--nonpharmacological management. Wien Med Wochenschr. 163(9-10), 228-35. DOI: 10.1007/s10354-013-0181-9.

4. Bennell, K. (2013). Physiotherapy management of hip osteoarthritis. J Physiother. 59(3), 145-57. DOI: 10.1016/S1836-9553(13)70179-6.

5. Krauss, I., Steinhilber, B. \& Haupt, G. (2011). Efficacy of conservative treatment regimes for hip osteoarthritis--evaluation of the therapeutic exercise regime "Hip School": a protocol for a randomised, controlled trial. BMC Musculoskelet Disord. 12-270. DOI: 10.1186/1471-2474-12-270.

6. Czyżewska, A., Glinkowski, WM. \& Walesiak, K. (2014). Effects of preoperative physiotherapy in hip osteoarthritis patients awaiting total hip replacement. Arch Med Sci. 10(5), 985-91. DOI : 10.5114/ aoms.2014.46218. 
7. Ethgen, O., Vanparijs, P. \& Delhalle, S. (2004). Social support and health-related quality of life in hip and knee osteoarthritis. Qual Life Res. 13(2), 321-30.

8. Hando, BR., Gill, NW. \& Walker, MJ. (2012). Short- and long-term clinical outcomes following a standardized protocol of orthopedic manual physical therapy and exercise in individuals with osteoarthritis of the hip: a case series. J Man Manip Ther. 20(4), 192-200. DOI: 10 $.1179 / 2042618612$ Y.0000000013.

9. Lourenço, S., Lucas, R. \& Araújo, F. (2014). Osteoarthritis medical labelling and health-related quality of life in the general population. Health Qual Life Outcomes. 12-146. DOI: 10.1186/s12955-014-0146-8.

10. Ackerman, IN., Busija, L. \& Tacey, MA. (2014). Performance of the assessment of quality of life measure in people with hip and knee joint disease and implications for research and clinical use. Arthritis Care Res (Hoboken). 66(3), 481-8. DOI: 10.1002/acr.22129.

11. Konstantinidis, GA., Aletras, VH. \& Kanakari, KA. (2014). Comparative validation of the WOMAC osteoarthritis and Lequesne algofunctional indices in Greek patients with hip or knee osteoarthritis. Qual Life Res. 23(2), 539-48. DOI: 10.1007/s11136-013-0490-x.

12. Figueiredo Neto, EM., Queluz, TT. \& Freire, BF. (2011). Physical activity and its association with quality of life in patients with osteoarthritis. Rev Bras Reumatol. 51(6), 544-9.

13. Lequesne, MG. (1997). The algofunctional indices for hip and knee osteoarthritis. J Rheumatol. (24), 779-781.

14. Boutron, I., Rannou, F. \& Jardinaud-Lopez, M. (2008). Disability and quality of life of patients with knee or hip osteoarthritis in the primary care setting and factors associated with general practitioners' indication for prosthetic replacement within 1 year. Osteoarthritis Cartilage. 16(9), 1024-31. DOI: 10.1016/j.joca.2008.01.001.

15. Salaffi, F., Carotti, M. \& Grassi, W. (2005). Health-related quality of life in patients with hip or knee osteoarthritis: comparison of generic and disease-specific instruments. Clin Rheumatol. 24(1), 29-37.

16. Angst, F., Aeschlimann, A. \& Stucki, G. (2001). Smallest detectable and minimal clinically important differences of rehabilitation intervention with their implications for required sample sizes using WOMAC and SF-36 quality of life measurement instruments in patients with osteoarthritis of the lower extremities. Arthritis Rheum. 45(4), 384-91.
17. Nadrian, H., Moghimi, N. \& Nadrian, E. (2012). Validity and reliability of the Persian versions of WOMAC Osteoarthritis Index and Lequesne Algofunctional Index. Clin Rheumatol. 31(7), 1097-102. DOI: 10.1007/ s10067-012-1983-7.

18. Basaran, S., Guzel, R. \& Seydaoglu, G. (2010). Validity, reliability, and comparison of the WOMAC osteoarthritis index and Lequesne algofunctional index in Turkish patients with hip or knee osteoarthritis. Clin Rheumatol. 29(7), 749-56. DOI: 10.1007/s10067-010-1398-2.

19. Voorn, VM., Vermeulen, HM. \& Nelissen, RG. (2013). An innovative care model coordinated by a physical therapist and nurse practitioner for osteoarthritis of the hip and knee in specialist care: a prospective study. Rheumatol Int. 33(7), 1821-8. DOI: 10.1007/s00296-012-2662-3.

20. Majani, G., Giardini, A. \& Scotti, A. (2005). Subjective impact of osteoarthritis flare-ups on patients' quality of life. Health Qual Life Outcomes. (16), 3-14.

21. van der Waal, JM., Terwee. \& van der Windt, DA (2005). Health-related and overall quality of life of patients with chronic hip and knee complaints in general practice. Qual Life Res. 14(3), 795-803.

22. van der Waal, JM., Terwee, CB. \& van der Windt, DA. (2005). The impact of non-traumatic hip and knee disorders on health-related quality of life as measured with the SF-36 or SF-12. A systematic review. Qual Life Res. 14(4), 1141-55.

23. Angst, F., Aeschlimann, A. \& Steiner, W. (2001). Responsiveness of the WOMAC osteoarthritis index as compared with the SF-36 in patients with osteoarthritis of the legs undergoing a comprehensive rehabilitation intervention. Ann Rheum Dis. 60(9), 834-40.

24. Benz, T., Angst, F. \& Lehmann, S. (2013). Association of the sense of coherence with physical and psychosocial health in the rehabilitation of osteoarthritis of the hip and knee: a prospective cohort study. BMC Musculoskelet Disord. 4(14), 159. DOI: 10.1186/1471-2474-14-159.

25. Angst, F., Verra, ML. \& Lehmann, S. (2013). Effects of inpatient rehabilitation in hip and knee osteoarthritis: a naturalistic prospective cohort study with intraindividual control of effects. Arch Phys Med Rehabil. 94(11), 2139-45. DOI: 10.1016/j.apmr.2013.03.026.

26. Fransen, M., McConnell, S. \& Hernandez-Molina, G. (2014). Exercise for osteoarthritis of the hip. Cochrane Database Syst Rev. 4:CD007912. DOI: 10.1002/14651858. 